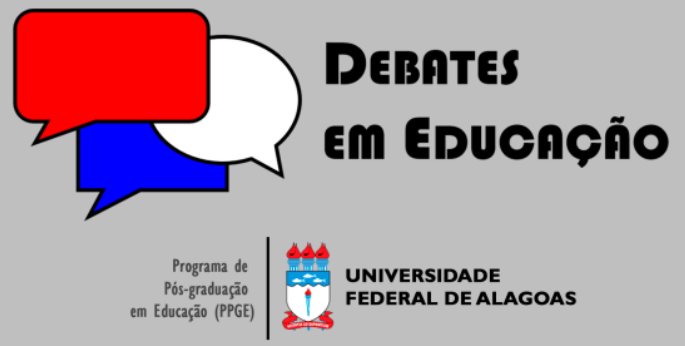

ISSN Eletrônico 2175-6600

Vol. 12 | Número Especial 2 | 2020

Jeferson Cardoso da Silva (9) iD

Instituto Federal de Educação, Ciência e Tecnologia de Rondônia (IFRO) jeferson.beu@gmail.com

Artur de Souza Moret 9 iD

Universidade Federal de Rondônia (UNIR) amoret@unir.br

\section{A EDUCAÇÃO ESCOLAR EM ASSENTAMENTOS DE HIDRELÉTRICAS: MEMÓRIAS DE UM POVO ESQUECIDO}

\section{RESUMO}

papel da educação escolar para as comunidades atingidas por barragens tem sido pouco debatido no meio científico. A ausência de políticas públicas voltadas para atender a demanda deste estrato populacional tem causado diversos problemas de ordem econômica, social e ambiental. Desta forma, esta pesquisa teve como objetivo geral retratar a importância dada à educação escolar sob o olhar das populações atingidas pela barragem da Usina Hidrelétrica (UHE) Santo Antônio. Para tanto, foi realizada uma pesquisa de campo nos 7 assentamentos da referida UHE. A ferramenta utilizada foi o questionário, 93 indivíduos participaram da amostra. Os resultados evidenciam que as recordações dos entrevistados acerca da escola remetem a um ambiente importante e significativo para a comunidade.

Palavras-chave: Educação escolar. Atingidos por barragem. Políticas públicas.

\section{SCHOOL EDUCATION IN HYDROELECTRIC SETTLEMENTS: MEMORIES OF A FORGOTTEN PEOPLE}

\begin{abstract}
The role of school education for communities affected by dams has been little debated in the scientific community. The absence of public policies aimed at meeting the demand of this population stratum has caused several economic, social and environmental problems. Thus, this research aimed to portray the importance given to school education from the perspective of the populations affected by the dam of Santo Antônio Hydroelectric Power Plant (HPP). To this end, a field research was carried out in the 7 settlements of the referred HPP. The tool used was the questionnaire, 93 individuals participated in the sample. The results show that the interviewees' memories about the school refer to an important and significant environment for the community.
\end{abstract}

Keywords: Schooling. Affected by dam. Public policy.

Submetido em: 12/09/2019

Aceito em: 12/08/2020

Publicado em: 30/I2/2020

dc http://dx.doi.org//0.28998/2175-6600.2020v12nEsp2p37-59 


\section{INTRODUÇÃO}

Historicamente, o Estado de Rondônia foi marcado por ciclos exploratórios. O prelúdio destes ciclos foi o extrativismo, posteriormente, o ciclo da borracha; a construção da Estrada de Ferro MadeiraMamoré; a extração do Ouro e da Cassiterita; a exploração de madeira e a criação de gado. Atualmente, culminando como último e mais recente ciclo, temos o das hidrelétricas (ARAÚJO e MORET, 20 I6).

Neste sentido, apresentam-se os principais motivos que, interligados, encaminharam-se para a temática escolhida nesta pesquisa. Selecionou-se a educação escolar pelo seu papel enquanto instituição social e como fator objetivo da constituição do território, em virtude de sua importância na formação da sociedade, suprimido no Plano Básico Ambiental (PBA) e projeto de implantação dos assentamentos.

Destaca-se a tentativa de simplificação em sistemas complexos como a construção de Usinas Hidroelétricas (UHE), que ignoram componentes objetivos e subjetivos dos deslocados compulsoriamente, gerando uma negação deste novo território. No atual estágio da ciência, os sistemas são explicados por abordagens múltiplas, complexas, em contraposição à simplificação. Obras deste porte quando feitas por meio da racionalização do pensamento, geram a alienação do trabalho, a devastação do ambiente, a poluição da atmosfera, entre outros danos.

Entende-se que as relações existentes entre o ser humano com seu habitat superam o aspecto da materialidade; ela têm raízes cosmológicas, desta forma, na medida em que estes fundamentos são anulados, o sujeito apresenta uma relação de negação com o território, uma sensação de não pertencimento e não participação que, para Carracedo (2000) se enquadra no conceito de cidadania complexa, ou seja, na dialética entre pertencer e participar de um determinado grupo social.

Dessa forma, o objetivo geral desta pesquisa foi retratar a importância dada para a educação escolar na visão das populações atingidas pela barragem da UHE Santo Antônio, no Rio Madeira, em Porto Velho - RO. Os assentamentos criados em função desta obra são: Novo Engenho Velho; Riacho Azul; São Domingos (margem esquerda do rio); Nova Vila de Teotônio; Parque dos Buritis; Santa Rita e Morrinhos (margem direita do rio).

Esta pesquisa foi estruturada seguindo os padrões editoriais e normas técnicas vigentes no país, de modo que, os tópicos seguintes apresentam: o referencial teórico (que dará sustentação aos argumentos da pesquisa); os resultados e discussões (expondo os dados coletados e análises feitas a partir destes); a conclusão (trazendo o desfecho da pesquisa, suas limitações e sugestões) e as referências (com o rol de autores consultados). 


\section{REVISÃO BIBLIOGRÁFICA}

No país há investimentos significativos na oferta de energia elétrica e tão pouco em gasto consciente. Da mesma forma, entende-se, conforme demonstrado por vários autores (GIONGO et. al., 20I5; BERMANN, 2002, 2007; FEARNSIDE, 1995, 2015; 2019; VAINER, 2007, 2008; MORET e GUERRA, 2009; MORET e SILVA, 2010) que os investimentos na reparação dos danos ao ambiente e à sociedade são pouco significativos.

Entende-se, na perspectiva desta pesquisa, que a educação escolar é parte integrante e fundamental do complexo social que abrange, entre outras coisas, as relações de poder, os usos e costumes, a cultura, enfim, são questões inerentes à composição do território. Nesse sentido, o território é pensado, segundo Santos (1999, p. 7), como "o lugar em que desembocam todas as ações, todas as paixões, todos os poderes, todas as forças, todas as fraquezas, isto é, onde a história do homem plenamente se realiza a partir das manifestações da sua existência".

Território não é somente a união dos recursos naturais num espaço geográfico definido, tem que ser concebido como o local onde as características de um povo são formadas e conformadas. Deve-se considerá-lo como formador da identidade, para sentir-se parte daquele chão e que a este, nós estamos vinculados. No território, encontra-se uma perspectiva de sobrevivência, projeto de vida e futuro, que é citado no trabalho de Escobar (20 |4, p. 88), como "espaço coletivo, composto por todo o lugar necessário e indispensável onde homens e mulheres, jovens e adultos, criam e recriam suas vidas" (tradução nossa).

A educação escolar na República Federativa do Brasil tem sido excludente e dualista, desde quando este ainda era uma colônia, favorecendo, desta forma, a classe dominante. Segundo Santos (2017, p. 72) "[... quando se refere ao campo essa exclusão aparece de forma ainda mais perceptível". No país, foi consagrado pela história um padrão agrário de acumulação de terra, que criou os latifúndios no século XX e favoreceu para que os governantes da época preterissem a formação escolar das comunidades de origem rural, usando como subterfúgio o argumento do paradigma agroexportador vigente naquele período.

Segundo Ponce (200I, p. 162), "[...] a educação tem sempre estado a serviço das classes dominantes, até o momento em que outra classe revolucionária consegue desalojá-las do poder e impor à sociedade a sua própria educação". Contudo, até que essa nova classe não esteja forte o suficiente, há uma aparente e intencional inércia por parte desta, no sentido de aguardar o momento exato do exaurimento da classe dominante para enfim, poder assediá-la. Historicamente, não se apresenta mais que duas revoluções no campo educacional: divisão da sociedade primitiva em sociedade de classes e substituição do feudalismo pela burguesia que, consoante afirmação de Ponce (200 I), gerou uma minoria de exploradores burgueses e uma massa gigantesca de proletários explorados. 
A educação brasileira dos últimos 50 anos, aproximadamente, tem sido marcada pelas tendências liberais, ora conservadora ora renovada (SAVIANI, 198I). Não há mudanças consistentes nessas práticas que são obsoletas e compactuantes com o sistema capitalista em que vivemos. De acordo com Libâneo (2002, p. 6), "evidentemente tais tendências se manifestam, concretamente, nas práticas escolares e no ideário pedagógico de muitos professores, ainda que estes não se dêem conta dessa influência".

A educação escolar foi pensada nesta pesquisa não como panaceia, único determinante para esclarecer os problemas, mas, como item imprescindível na reinvenção do mundo e parte da complexidade do sistema sociedade. A educação escolar surge, segundo Freire (200 I, p. I0), "como processo de conhecimento, formação política, manifestação ética, procura da boniteza, capacitação científica e técnica, a educação é prática indispensável aos seres humanos e deles específica na História como movimento, como luta".

Reforça-se que, nesta pesquisa, defende-se uma escola capaz de uma formação omnilateral proposta por Marx e apresentada por Manacorda (2010, p. 94), possibilitando "[...] um desenvolvimento total, completo, multilateral, em todos os sentidos, das faculdades e das forças produtivas, das necessidades e da capacidade da sua satisfação", pois todo ser humano alienado por outro, também é/está alienado da própria natureza.

\section{METODOLOGIA}

A presente pesquisa é parte de Tese de doutorado aprovada pelo Comitê de Ética sob número de protocolo 2.444.8I 4. Está caracterizada como uma pesquisa social e, deste modo, de cunho qualitativo (MINAYO, 200 I). A população foi composta pelas comunidades atingidas pela construção da UHE Santo Antônio, a saber: Novo Engenho Velho, Riacho Azul e São Domingos (margem esquerda do Rio Madeira), Nova Vila de Teotônio, Parque dos Buritis, Santa Rita e Morrinhos (margem direita do Rio Madeira).

A amostragem não probabilística ocorreu através da aplicação de questionário com questões abertas e fechadas buscando informações diretamente com os moradores das regiões afetadas, em todos os 7 reassentamentos, totalizando 93 indivíduos. A proposta foi realizar uma análise que retratasse a importância dada pelas comunidades deslocadas para a educação escolar.

Tabelas cruzadas foram produzidas por meio do programa IBM SPSS Statistics versão 20, que facilitou a organização do pensamento e tratamento que foi aplicado nos dados coletados por meio do questionário, pois a partir da criação das tabelas cruzadas, tanto a parte expressa basicamente em números quanto a parte mais descritiva em que teria que discorrer e aprofundar no discurso dos entrevistados, foi permeada por todo este processo de quantificação das informações. 
A análise de conteúdo (BARDIN, 1979) foi utilizada para entender os dados e como extrair dali os resultados. A primeira coleta foi realizada nos assentamentos da margem esquerda. Nestes, foram aplicados 34 questionários. Nos reassentamentos da margem direita foram consultados 59 indivíduos. Foi possível realizar a coleta em toda a amostra em 3 sábados consecutivos.

Apesar do mês de março ser um período de inverno amazônico, ou seja, chove-se bastante, conseguiu-se acessar todas as comunidades, apesar de as estradas de acesso aos assentamentos de ambas as margens (esquerda e direita), com exceção de Parque dos Buritis que fica na região urbana de Jaci Paraná, encontrarem-se em más condições de tráfego.

\section{RESULTADOS E DISCUSSÕES}

Iniciou-se visando revelar a existência ou não de escola dentro da antiga comunidade. Para tanto, perguntou-se: havia escola na antiga comunidade? Como resposta, os entrevistados poderiam informar: a) sim; b) se não, como faziam para ir à escola.

Tabela I - Percentual de respostas entre Assentamento x Tinha Escola na antiga Comunidade

\begin{tabular}{|c|c|c|c|c|c|}
\hline & & & Sim & Não & Total \\
\hline \multirow{14}{*}{ 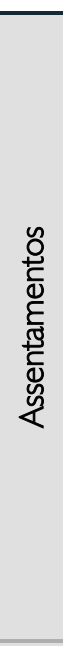 } & \multirow{2}{*}{ Novo Engenho Velho } & Contagem & 10 & 3 & 13 \\
\hline & & $\%$ em Assent & $76,9 \%$ & $23,1 \%$ & $100 \%$ \\
\hline & \multirow{2}{*}{ Riacho Azul } & Contagem & 9 & - & 9 \\
\hline & & $\%$ em Assent & $100 \%$ & $0,0 \%$ & $100 \%$ \\
\hline & \multirow{2}{*}{ São Domingos } & Contagem & 11 & 1 & 12 \\
\hline & & $\%$ em Assent & $91,7 \%$ & $8,3 \%$ & $100 \%$ \\
\hline & \multirow{2}{*}{ Nova Vila de Teotônio } & Contagem & 14 & - & 14 \\
\hline & & $\%$ em Assent & $100 \%$ & $0,0 \%$ & $100 \%$ \\
\hline & \multirow{2}{*}{ Parque dos Buritis } & Contagem & 16 & - & 16 \\
\hline & & $\%$ em Assent & $100 \%$ & $0,0 \%$ & $100 \%$ \\
\hline & \multirow{2}{*}{ Santa Rita } & Contagem & 16 & - & 16 \\
\hline & & $\%$ em Assent & $100 \%$ & $0,0 \%$ & $100 \%$ \\
\hline & \multirow{2}{*}{ Morrinhos } & Contagem & 8 & 5 & 13 \\
\hline & & $\%$ em Assent & $61,5 \%$ & $38,5 \%$ & $100 \%$ \\
\hline \multirow{2}{*}{\multicolumn{2}{|c|}{ Total }} & Contagem & 84 & 9 & 93 \\
\hline & & $\%$ em Assent & $90,3 \%$ & $9,7 \%$ & $100 \%$ \\
\hline
\end{tabular}

Fonte: Elaborado pelo próprio autor (20|8).

A Tabela I possibilita entender que nos assentamentos RAZ, NVT, PBU e SRI, I00\% dos entrevistados disseram sim, tinha escola na comunidade. Nessas localidades a composição peculiar dos reassentamentos não interferiu na homogeneidade dos resultados. Os números totais de Sim, somaram 90,3\% dos entrevistados (84 pessoas) contra 9,7\% dizendo Não (9 pessoas).

Somente em 3 (três) dos 7 (sete) reassentamentos houve entrevistados alegando que não tinham escola em sua comunidade. Assim, obteve-se em NEV 76,9\% ( 10 pessoas) dizendo que Sim, tinha escola 
na comunidade, enquanto que 23,1\% (3 pessoas) alegando não terem escola na comunidade, estes últimos dizendo como iam à escola:

\author{
Entrevistado I: Atravessava o rio \\ Entrevistado 2: Na outra margem do rio \\ Entrevistado 3: Utilizava voadeira, o resto ia de pé \\ Dados da pesquisa (2018).
}

Em SDO 9I,7\% (I I pessoas) atestando que tinha escola na comunidade, contra 8,3\% (I pessoa) relatando que não havia escola em sua comunidade, dizendo que para ir à escola "Atravessava o rio".

Já em MOR, 6I,5\% (8 pessoas) citaram ter escola na comunidade, enquanto 38,5\% (5 pessoas) indicaram que não tinha escola. Todos os que disseram não ter escola contaram como faziam para ir:

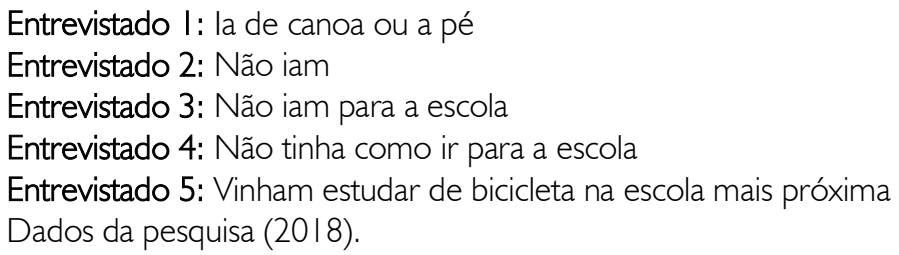

É importante destacar que, apesar das dificuldades por morarem em regiões periféricas e com poucas condições de acesso a alguns bens comuns como educação e saúde, salta aos olhos a resiliência para buscar qualidade de vida para si e seus familiares. Isso fica evidente quando contam suas trajetórias até a escola, seja de canoa atravessando o rio, indo de pé ou bicicleta por caminhos insalubres, ou às vezes, por absoluta falta de condições, sendo impossibilitados de frequentar a escola, restando apenas a frustração, perceptível no olhar destes entrevistados.

Entretanto, para os anos de 2015 a 2024, a Prefeitura Municipal de Porto Velho em parceria com órgãos dos poderes Executivo, Legislativo e Sociedade Civil Organizada, estabeleceram critérios e metas para as demandas educacionais do território. Constam no Plano Municipal de Educação (PME) de Porto Velho (2015, p. 14) "[...] que o município possa atingir a consecução das diretrizes e metas propostas estrategicamente, a fim de assegurar que a educação pública no Município de Porto Velho possa alargar os passos, rumo ao topo dos indicadores de qualidade na educação nos próximos dez anos".

Ainda assim, há relatos de superação no sentido de formação educacional formal, pois alguns pais contam a vitória de seus filhos com a conclusão do ensino médio (na capital) e posterior ingresso na universidade. No Brasil, cerca de 60\% da população concluinte do Ensino Médio não ingressa em curso superior (PME, 20 I5, p. 70). A LDB (BRASIL, 1996) conferiu à educação escolar no meio rural, algumas especificidades próprias da diversidade do campo, destacadas nos artigos 23, 26 e 28 que tratam de questões pedagógicas e organização do tempo escolar. Ainda assim o poder público insiste em negligenciar essas comunidades.

Segundo Saviani ( 198 I ; 2008) tamanho é o poder da classe dominante (elite) frente aos dominados (marginalizados) que, sob a ótica da violência simbólica, o domínio é tal que qualquer ação que vise a 
reverter o cenário de dominação é inócua, de tal modo que, ao utilizar a educação escolar como ferramenta de superação, esta acaba por reforçar as diferenças, atuando como agente dos dominantes.

Partiu-se, desta forma, perguntando aos entrevistados se todas as pessoas em idade escolar na família frequentavam a escola. A Tabela 2 apresenta os resultados.

Tabela 2 - Percentual do cruzamento: Assentamento x todos em idade escolar vão para Escola?

\begin{tabular}{|c|c|c|c|c|c|}
\hline & & & Sim & Não & Total \\
\hline \multirow{14}{*}{ 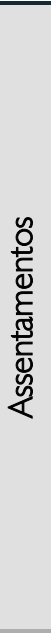 } & \multirow{2}{*}{ Novo Engenho Velho } & Contagem & 13 & - & 13 \\
\hline & & $\%$ em Assent & $100 \%$ & - & $100 \%$ \\
\hline & \multirow{2}{*}{ Riacho Azul } & Contagem & 9 & - & 9 \\
\hline & & $\%$ em Assent & $100 \%$ & - & $100 \%$ \\
\hline & \multirow{2}{*}{ São Domingos } & Contagem & | | & I & 12 \\
\hline & & $\%$ em Assent & $91,7 \%$ & $8,3 \%$ & $100 \%$ \\
\hline & \multirow{2}{*}{ Nova Vila de Teotônio } & Contagem & 14 & - & 14 \\
\hline & & $\%$ em Assent & $100 \%$ & - & $100 \%$ \\
\hline & \multirow{2}{*}{ Parque dos Buritis } & Contagem & 16 & - & 16 \\
\hline & & $\%$ em Assent & $100 \%$ & - & $100 \%$ \\
\hline & \multirow{2}{*}{ Santa Rita } & Contagem & 16 & - & 16 \\
\hline & & $\%$ em Assent & $100 \%$ & - & $100 \%$ \\
\hline & \multirow{2}{*}{ Morrinhos } & Contagem & 9 & 4 & 13 \\
\hline & & $\%$ em Assent & $69,2 \%$ & $30,8 \%$ & $100 \%$ \\
\hline & \multirow{2}{*}{ Total } & Contagem & 88 & 5 & 93 \\
\hline & & $\%$ em Assent & $94,6 \%$ & $5,4 \%$ & $100 \%$ \\
\hline
\end{tabular}

Fonte: Elaborado pelo próprio autor (20 |8).

As opções de resposta na Tabela 2 foram: sim; não, por quê? Neste caso, nesta segunda opção, o entrevistado poderia complementar ou não sua resposta. Depreende-se da Tabela 2 que dos 7 reassentamentos 5 indicam que 100\% das pessoas em idade escolar na família frequentavam a escola (94,6\% dos entrevistados, 88 pessoas) disseram não, 5 pessoas (4 em MOR e I em SDO - 5,4\%) indicando as seguintes razões:

Entrevistado I: desistência

Entrevistado 2: não tinha escola perto

Entrevistado 3: não tinha filhos morando

Entrevistado 4: ários motivos: distância da escola e falta de motivação dos pais".

Dados da pesquisa (20।8).

Assim, estes resultados fortalecem a ideia de importância da existência da escola na comunidade, pois isto perpassa pelos prédios existentes, bem como pela possibilidade de frequentar escolas em locais próximos, que atualmente, se caracterizam por três possibilidades: I) para os alunos do nível fundamental II (do $6^{\circ}$ ao $9^{\circ}$ anos) que moram na margem esquerda acima da barragem o deslocamento é feito de barco até Nova Vila Teotônio, apesar de ter escola em Riacho Azul (esta atende alunos até o primeiro nível fundamental I - $1^{\circ}$ ao $5^{\circ}$ anos); 2) aqueles que moram abaixo do eixo da barragem deslocam-se de ônibus público para a localidade DNIT (nome dado para o assentamento da população ribeirinha afetada pela construção da ponte sobre o Rio Madeira, reassentada na margem esquerda do rio poucos 
quilômetros após a cabeceira da ponte); 3) os estudantes que estão no ensino médio e moram na margem esquerda do Rio, vão para Porto Velho.

Os estudantes assentados na margem direita, a maior parte vai para Jaci Paraná, (distrito de Porto Velho). Na capital, somente as Escolas ao redor do Centro têm acolhido estes estudantes, ingressando em turmas em que o ensino e o tratamento oferecido não condizem com as demais turmas, segundo o relato informal de alguns pais. Independentemente de que lado do rio estiverem, o plano educacional do município (PME, 20I5, p. 50) no tocante à educação escolar no nível fundamental assegura que, ao estudante deve ser garantido o direito à aprendizagem, à promoção e ao prosseguimento em sua escolarização com sucesso, ressaltando que o poder público "[...] deve empenhar-se na promoção de uma cultura escolar acolhedora e respeitosa, que reconheça e valorize as experiências dos estudantes de forma individualizada, como fator de contribuição efetiva à inclusão escolar e ao direito de todos à educação".

A questão seguinte complementa o conteúdo da anterior, haja vista que nela, era perguntado se havia alguma pessoa em idade escolar na família que não estivesse na escola e, se possível, indicasse a idade desta pessoa. Como resposta, poderiam indicar: a) I fora da escola (I FE), b) 2 fora da escola (2FE), c) 3 fora da escola (3FE), nenhum fora da escola (NFE). A Tabela 3 discute os resultados do quantitativo de pessoas na família em idade escolar fora dela e em que idade se encontrava.

Tabela 3 - Percentual de respostas: Assentamento x Pessoas em idade escolar fora da Escola

\begin{tabular}{|c|c|c|c|c|c|c|c|c|}
\hline & & & I FE & $2 \mathrm{FE}$ & $3 \mathrm{FE}$ & $4 \mathrm{FE}$ & NFE & tal \\
\hline \multirow{14}{*}{ 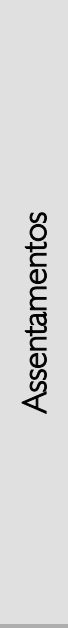 } & \multirow{2}{*}{$\begin{array}{c}\text { Novo Engenho } \\
\text { Velho }\end{array}$} & Contagem & 2 & - & - & - & 11 & 13 \\
\hline & & $\%$ & $15,4 \%$ & - & - & - & $84,6 \%$ & $100 \%$ \\
\hline & \multirow{2}{*}{ Riacho Azul } & Contagem & - & - & - & - & 9 & 9 \\
\hline & & $\%$ & - & - & - & - & $100 \%$ & $100 \%$ \\
\hline & \multirow{2}{*}{ São Domingos } & Contagem & - & - & - & - & 12 & 12 \\
\hline & & $\%$ & - & - & - & - & $100 \%$ & $100 \%$ \\
\hline & \multirow{2}{*}{$\begin{array}{l}\text { Nova Vila de } \\
\text { Teotônio }\end{array}$} & Contagem & - & - & - & - & 14 & 14 \\
\hline & & $\%$ & - & - & - & - & $100 \%$ & $100 \%$ \\
\hline & \multirow{2}{*}{ Parque dos Buritis } & Contagem & - & - & - & - & 16 & 16 \\
\hline & & $\%$ & - & - & - & - & $100 \%$ & $100 \%$ \\
\hline & \multirow{2}{*}{ Santa Rita } & Contagem & - & - & - & - & 16 & 16 \\
\hline & & $\%$ & - & - & - & - & $100 \%$ & $100 \%$ \\
\hline & \multirow{2}{*}{ Morrinhos } & Contagem & 1 & 1 & - & 1 & 10 & 13 \\
\hline & & $\%$ & $7,7 \%$ & $7,7 \%$ & - & $7,7 \%$ & $76,9 \%$ & $100 \%$ \\
\hline & \multirow{2}{*}{ Total } & Contagem & 3 & 1 & - & 1 & 88 & 93 \\
\hline & & $\%$ & $3,2 \%$ & $1,1 \%$ & - & $1,1 \%$ & $94,6 \%$ & $100 \%$ \\
\hline
\end{tabular}

Fonte: Elaborado pelo próprio autor (20|8).

Percebe-se, ao analisar a Tabela 3, que somente em dois (2) dos sete (7) assentamentos havia pessoas em idade escolar na família, fora da escola: NEV com 2 entrevistados ( I 5,4\%) ambos informando ter IFE com 13 anos de idade: e MOR com 23, I \% dos entrevistados (3 pessoas) cada um indicando uma 
quantia diferente: IFE, 2FE e 4FE. Somente um destes indicando a idade da pessoa ( 17 anos) quando esteve fora da escola.

Os demais reassentamentos RAZ, SDO, NVT, PBU e SRI informaram ter $100 \%$ das pessoas em idade escolar na família frequentando a escola. Este resultado vem ao encontro da perspectiva de que, por mais difícil que possa ser para o estudante chegar, permanecer e ter sucesso na escola, ainda que o Estado enquanto ente Federativo por vezes falte com suas obrigações, 94,6\% (88 pessoas) vêem na educação um caminho de possibilidades de alcançar seus objetivos de vida como cidadãos e seres humanos, ainda que a educação escolar não tenha sido capaz de mudar sua própria vida, pois a falta desta implica a saída dos jovens destes reassentamentos para buscar formação profissional e colocação no mercado de trabalho nas áreas urbanas.

Desde 2012 o Governo Federal, por meio do Ministério da Educação, instituiu um pacto para alfabetização na idade certa de modo que ao final do $3^{\circ}$ ano do Ensino Fundamental e até os 8 anos de idade toda criança esteja alfabetizada (PME, 20I5) ou seja, a lei vem sendo negligenciada.

Segundo Moret e Silva (2010) a obra das UHEs do Madeira apresentam falhas de obediência às normas legais (Legislação Ambiental e o Estatuto da Cidade) desde a fase inicial dos estudos. Em boa parte dos casos os estudos de impacto ambiental não levam em consideração a complexidade dos aspectos socioambientais, políticos, redundando em obras mitigadoras e compensatórias morosas e ineficazes.

Buscando respostas e procurando compreender estas e outras questões, prossegue-se questionando aos entrevistados se havia portadores de necessidades especiais (PNE) nos reassentamentos. Com efeito, perguntou-se: na comunidade existia alguma criança ou adolescente portador de necessidade especial (cadeirante, síndrome de Down, deficiência visual)?. Como opções de resposta havia: a) Sim (informando qual era a necessidade especial caso lembrasse), b) não, c) não sei.

Tabela 4 - Percentual de respostas entre Assentamento x PNE's na comunidade Antiga

\begin{tabular}{|c|c|c|c|c|c|c|}
\hline & & & Sim & Não & Não sei & Total \\
\hline \multirow{14}{*}{ 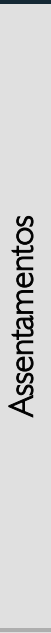 } & \multirow{2}{*}{ Novo Engenho Velho } & Contagem & - & 13 & - & 13 \\
\hline & & $\%$ em Assent & $0,0 \%$ & $100 \%$ & $0,0 \%$ & $100 \%$ \\
\hline & \multirow{2}{*}{ Riacho Azul } & Contagem & - & 9 & - & 9 \\
\hline & & $\%$ em Assent & $0,0 \%$ & $100 \%$ & $0,0 \%$ & $100 \%$ \\
\hline & \multirow{2}{*}{ São Domingos } & Contagem & 2 & 8 & 2 & 12 \\
\hline & & $\%$ em Assent & $16,7 \%$ & $66,7 \%$ & $16,7 \%$ & $100 \%$ \\
\hline & \multirow{2}{*}{ Nova Vila de Teotônio } & Contagem & 4 & 7 & 3 & 14 \\
\hline & & $\%$ em Assent & $28,6 \%$ & $50,0 \%$ & $21,4 \%$ & $100 \%$ \\
\hline & \multirow{2}{*}{ Parque dos Buritis } & Contagem & 2 & 7 & 7 & 16 \\
\hline & & $\%$ em Assent & $12,5 \%$ & $43,8 \%$ & $43,8 \%$ & $100 \%$ \\
\hline & \multirow{2}{*}{ Santa Rita } & Contagem & 4 & 9 & 3 & 16 \\
\hline & & $\%$ em Assent & $25,0 \%$ & $56,3 \%$ & $18,8 \%$ & $100 \%$ \\
\hline & \multirow{2}{*}{ Morrinhos } & Contagem & 9 & 3 & I & 13 \\
\hline & & $\%$ em Assent & $69,2 \%$ & $23,1 \%$ & $7,7 \%$ & $100 \%$ \\
\hline & \multirow{2}{*}{ Total } & Contagem & 21 & 56 & 16 & 93 \\
\hline & & $\%$ em Assent & $22,6 \%$ & $60,2 \%$ & $17,2 \%$ & $100 \%$ \\
\hline
\end{tabular}

Fonte: Elaborado pelo próprio autor (20।8). 
Observa-se, na Tabela 4, nos assentamentos da margem esquerda, NEV e RAZ I00\% informando a alternativa Não. Em SDO, 66,7\% (8 pessoas) indicando Não, enquanto 16,7\% (2 pessoas) anotando Não sei, e 16,7\% (2 pessoas) dizendo que Sim, e um destes informando "Síndrome de Down" como sendo a necessidade especial.

Nos reassentamentos da margem direita percebe-se uma maior distribuição das respostas. Em NVT 50\% (7 pessoas) dizendo Não, 21 ,4\% (3 pessoas) alegando Não sei, 28,6\% (4 pessoas) indicando que Sim, havia PNE nas seguintes especialidades:

Entrevistado I: deficiência Física

Entrevistado 2: dificuldade de locomoção e psiquiátrico.

Dados da pesquisa (20|8)

Em PBU, ao mesmo tempo com 43,8\% ( 14 pessoas ao todo) responderam Não e Não sei, enquanto $12,5 \%$ (2 pessoas) respondendo que Sim, porém sem indicar a necessidade especial. No assentamento SRI, 56,3\% (9 pessoas) disseram Não, 18,8\% (3 pessoas) indicando Não sei, e 25\% (4 pessoas) dizendo que Sim, informando as necessidades especiais:

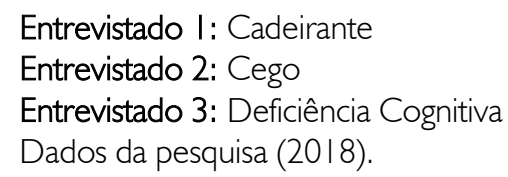

No assentamento MOR, 23, I\% (3 pessoas) disseram Não, 7,7\% ( I pessoa) disse Não sei, e 69,2\% (9 pessoas) assegurando que Sim, informando as necessidades especiais:

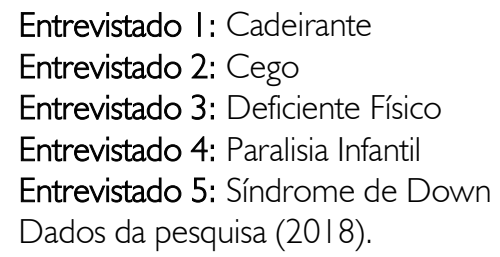

Quando analisados conjuntamente, infere-se que 60,2\% (56 do total de entrevistados) informaram a opção Não, 17,2\% ( 16 pessoas) disseram não saber e, 22,6\% (2I pessoas) atestando que Sim, sendo a necessidade mais comum a de origem física, ou seja, que necessitaria de acessibilidade na escola. Apesar deste ponto não ter sido efetivamente levantado, depreende-se que não havia cuidados especiais para estes estudantes, pois quando se questionou acerca da estrutura física da escola, não aparece menção alguma sobre aspectos de acessibilidade nas escolas, quiçá inclusão destes estudantes especiais das antigas comunidades.

Segundo a Secretaria Municipal de Educação de Porto Velho (PME, 20I5, p. 34) "[...] apesar dos investimentos em educação e dos avanços tecnológicos do século XXI, a infra estrutura das instituições de ensino ainda não contempla de forma satisfatória as condições plenas ao atendimento educacional. Nesse 
sentido, faz-se necessário que na definição orçamentária do município sejam priorizados recursos financeiros, que permitam a melhoria do espaço físico escolar e do seu entorno".

Adiante, indagou-se aos entrevistados como era a educação oferecida nas escolas das antigas comunidades. Como alternativas de resposta para este questionamento havia: a) ótimo; b) bom, c) razoável, d) ruim, e) não sei. Complementarmente o entrevistado poderia informar o porquê da resposta.

Tabela 5 - Percentual de respostas entre Assentamento x como era a Educação Escolar \begin{tabular}{l|c|c|c|c} 
Ótimo & Bom & Razoável & Ruim Não sei Total \\
\hline
\end{tabular}

\begin{tabular}{|c|c|c|c|c|c|c|c|c|}
\hline \multirow{14}{*}{ 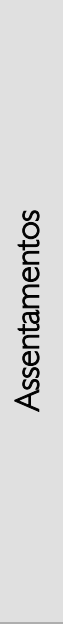 } & \multirow{2}{*}{ Novo Engenho Velho } & Contagem & 2 & 5 & 5 & - & 1 & 13 \\
\hline & & $\%$ & $15,4 \%$ & $38,5 \%$ & $38,5 \%$ & $0,0 \%$ & $7,7 \%$ & $100 \%$ \\
\hline & \multirow{2}{*}{ Riacho Azul } & Contagem & 1 & 2 & 6 & - & - & 9 \\
\hline & & $\%$ & $11,1 \%$ & $22,2 \%$ & $66,7 \%$ & $0,0 \%$ & $0,0 \%$ & $100 \%$ \\
\hline & \multirow{2}{*}{ São Domingos } & Contagem & 1 & 5 & 4 & - & 2 & 12 \\
\hline & & $\%$ & $8,3 \%$ & $41,7 \%$ & $33,3 \%$ & $0,0 \%$ & $16,7 \%$ & $100 \%$ \\
\hline & \multirow{2}{*}{ Nova Vila de Teotônio } & Contagem & - & 12 & 1 & 1 & - & 14 \\
\hline & & $\%$ & $0,0 \%$ & $85,7 \%$ & $7,1 \%$ & $7,1 \%$ & $0,0 \%$ & $100 \%$ \\
\hline & \multirow{2}{*}{ Parque dos Buritis } & Contagem & - & 8 & 5 & 3 & - & 16 \\
\hline & & $\%$ & $0,0 \%$ & $50,0 \%$ & $31,3 \%$ & $18,8 \%$ & $0,0 \%$ & $100 \%$ \\
\hline & \multirow{2}{*}{ Santa Rita } & Contagem & 3 & 7 & 6 & - & - & 16 \\
\hline & & $\%$ & $18,8 \%$ & $43,8 \%$ & $37,5 \%$ & $0,0 \%$ & $0,0 \%$ & $100 \%$ \\
\hline & \multirow{2}{*}{ Morrinhos } & Contagem & - & 3 & 3 & 1 & 6 & 13 \\
\hline & & $\%$ & $0,0 \%$ & $23,1 \%$ & $23,1 \%$ & $7,7 \%$ & $46,2 \%$ & $100 \%$ \\
\hline & \multirow{2}{*}{ Total } & Contagem & 7 & 42 & 30 & 5 & 9 & 93 \\
\hline & & $\%$ & $7,5 \%$ & $45,2 \%$ & $32,3 \%$ & $5,4 \%$ & $9,7 \%$ & $100 \%$ \\
\hline
\end{tabular}

Fonte: Elaborado pelo próprio autor (2018).

Em consonância com a Tabela 5, nos assentamentos da margem esquerda não houve declaração da opção Ruim. Em NEV consideravam Ótimo: ( 15,4\% - 2 pessoas) informando o porquê:

Entrevistado I: Didática da professora boa e a mesma nunca faltava Entrevistado 2: Excelentes profissionais, aulas constantes Dados da pesquisa (20|8)

Consideraram Bom: (38,5\% - 5 pessoas) indicando como motivos de consideram bom:

Entrevistado 3: porque as crianças passavam de ano;

Entrevistado 4: porque era bom para as crianças ler;

Entrevistado 5: professores eram bons e atenciosos. Aprenderam muito meus meninos, mesmo começando atrasados no estudo

Dados da pesquisa (20|8).

Achando Razoável: (38,5\% - 5 pessoas) declarando os seguintes porquês:

Entrevistado 6:poucos professores, muitas turmas em uma só sala; Entrevistado 7: aprendiam um pouco;

Entrevistado 8: falta de recursos pedagógicos;

Entrevistado 9: falta de materiais didáticos.

Dados da pesquisa (20|8).

No assentamento RAZ foi considerado Ótimo por: ( I I, I\% - I pessoa) indicando que o motivo era o "Respeito presente entre as relações". Achavam Bom: (22,2\% - 2 pessoas) uma delas alegando que 
a razão era porque "Aprenderam bastantes coisas: ler e escrever". Disseram Razoável: (66,7\% - 6 pessoas) apontando os motivos:

Entrevistado I: o ensino não era de qualidade;

Entrevistado 2: não tinha como terminar os estudos;

Entrevistado 3: Tinha semana que o professor não vinha.

Dados da pesquisa (2018).

Em SDO I pessoa achava Ótimo: (8,3\% - I pessoa) dizendo que era em função dos "Professores bons". Consideraram Bom: SDO (4I,7\% - 5 pessoas) elegendo como razão:

Entrevistado I: tinha apenas uma professora e era ótima;

Entrevistado 2: pela oportunidade de aprendizado e o resultado adquirido;

Entrevistado 3: a comunidade ficava sabendo ler.

Dados da pesquisa (20|8)

Entendiam que era Razoável: SDO (33,3\% - 4 pessoas) uma destas alegando que "A educação na zona rural precisa melhorar em tudo". Os demais entrevistados disseram Não sei: ( $6,7 \%$ - 2 pessoas).

Nos reassentamentos da margem direita, percebe-se em NVT, com a opção Bom: (85,7\% - I2 pessoas) com os seguintes porquês:

Entrevistado I: culpavam a direção da escola por os filhos não saberem ler;

Entrevistado 2: o ensino era bom

Entrevistado 3: fatores que contribuíram: renda com os pais, acesso de qualidade, facilidade dos professores chegar a vila;

Entrevistado 4: lá tinha muitos recursos para os professores virem a escola. Mais zeladores, melhor cuidada;

Entrevistado 5: só tinha ela mesmo

Entrevistado 6: os professores ensinavam muito bem. Não passava quem não queria estudar

Entrevistado 7: era um sistema limitado. Era cultural dos pais não ajudarem nessa continuidade;

Entrevistado 8: os alunos tinham o mesmo nível dos colégios da cidade

Dados da pesquisa (20|8).

Achavam-na Razoável: (7, I\% - I pessoa) e a razão apresentada foi "ensino ruim, alunos mal formados". Considerou Ruim: (7,1\% - I pessoa) e o motivo foi "por falta de formação profissional dos professores".

Em PBU houve indicação de Bom: (50\% - 8 pessoas) somente uma indicando o porquê: "sempre teve muita procura por vagas". Consideraram-na Razoável: (31,3\% - 5 pessoas) com uma justificativa de "melhor do que hoje, falta de professores". Os demais achavam Ruim: (I8,8\% - 3 pessoas) sem informar o motivo da resposta.

No assentamento de SRI destacaram a opção Ótimo: ( I 8,8\% - 3 pessoas) declarando os seguintes motivos:

Entrevistado I: era o único lugar que tínhamos. Ficamos muitos dias sem aula;

Entrevistado 2: a maioria dos jovens deram seguimento aos estudos, estão se formando na faculdade;

Dados da pesquisa (20|8)

Elegeram-na Bom: (43,8\% - 7 pessoas) destacando como causa: 
Entrevistado 3: a escola era organizada;

Entrevistado 4: com a dificuldade que a comunidade apresentava tinha professor;

Entrevistado 5: era ótimo;

Entrevistado 6: pertinho de casa

Dados da pesquisa (20 |8)

Achavam-na Razoável: (37,5\% - 6 pessoas) um destes dizendo porquê: "toda escola tem reclamação, e ela tinha".

Em MOR achavam Bom: (23, I\% - 3 pessoas) todos estes declararam o motivo:

Entrevistado I: era bom porque ensina a ler;

Entrevistado 2: era muito boa;

Entrevistado 3: tinha apoio pedagógico.

Dados da pesquisa (20|8).

Consideraram Razoável: (23,1\% - 3 pessoas) destas, duas delas indicando as motivações das respostas:

Entrevistado 4: ausência de aulas;

Entrevistado 5: faltou mais dedicação, material, eram acomodados

Dados da pesquisa (20 | 8).

Consideraram-na Ruim: (7,7\% - I pessoa) e Não sei: (46,2\% - 6 pessoas) ambas não informando a razão da escolha das respostas.

De modo geral, a Tabela 5 apresenta a maioria dos entrevistados dizendo que a educação oferecida nas escolas das antigas comunidades era ou Boa (45,2\% - 42 pessoas) ou Razoável (32,3\% - 30 pessoas). Observa-se, assim, que, mesmo com toda dificuldade já apresentada aqui (limitações de recursos humanos, pedagógicos, estruturais, etc.) a esperança com a educação escolar por mais que esta pareça não ter feito diferença na vida deles, se reflete quando se constata que $77,5 \%$ dos entrevistados consideraram-na Boa e Razoável.

Em sentido contrário ao cenário acima apresentado, Saviani (1981; 2008) citando Althusser e o conceito de Aparelho Ideológico de Estado (AIE), reflete que a escola enquanto AIE, trata de reproduzir as relações de exploração capitalista e, desta forma, inculcar nos estudantes a ideologia da classe dominante, estes então passam a aceitar de modo natural sua condição marginal.

O poder de compra e a persuasão do capital são tão fortes nesses casos que facilmente se constrói um espectro de melhorias no imaginário das pessoas, utilizando os meios de comunicação (AlE - rádio, tv, internet) e, desta maneira, pouco a pouco começam a sucumbir. Fearnside (2019) aponta diversas manobras do governo para se fazer aprovar os projetos de grandes construções de UHEs, assim como isso pode e vem afetando as populações que são deslocadas compulsoriamente.

Quando um empreendimento deste porte é anunciado em uma determinada localidade, os Aparelhos Repressivos do Estado (AIR - governo, polícia, tribunais) começam a agir para dificultar (ainda mais) a chegada de políticas públicas que possam favorecer o local e fragilizam a comunidade. No caso de 
NVT, segundo relato informal durante a pesquisa de campo, ações da Polícia Ambiental passaram a ser mais ostensivas e agressivas, apreendendo materiais de pesca, aplicando multas, ou seja, deixando-os vulneráveis economicamente. Assim, quando os negociadores do empreendimento chegam aos locais, fica mais fácil convencer os moradores em deixar o local, haja vista que ali já não tem mais sossego para trabalhar e viver. Dessa forma, o charme da oferta pela sua terra se torna irresistível, pois de certo modo não teriam outra saída que não aceitar a vil proposta: suas casas, seus terrenos, sua história, sua cultura, suas lembranças por uma carta de crédito ou outra casa de alvenaria no reassentamento no lugar de sua atual residência.

Passou-se desta forma, ao derradeiro questionamento: qual a sua melhor recordação da escola na antiga comunidade? Esta pergunta foi totalmente aberta, dando espaço para que os entrevistados pudessem usar a imaginação para respondê-la. Portanto, a apresentação dos resultados não será feita por meio de tabela e sim, exposta assentamento por assentamento. No assentamento de Nova Engenho Velho temos as seguintes considerações:

\footnotetext{
Entrevistado I: datas comemorativas, São João e Santo Antônio;

Entrevistado 2: didática da professora era boa;

Entrevistado 3: só para as crianças ir a escola;

Entrevistado 4: brincadeiras e subir nas árvores;

Entrevistado 5: era de madeira pintadinha;

Entrevistado 6: era agradável;

Entrevistado 7: era bem simples, de madeira coberta de palha;
}

Entrevistado 8: quando as crianças começaram a estudar foi ótimo, pois não havia escola na antiga comunidade;

Entrevistado 9: era pequena e tinha muita gente correndo na hora da merenda, estudávamos até na varanda da escola;

Entrevistado I0: ótima escola, educação ao acesso das crianças;

Entrevistado II: não ter violência;

Entrevistado 12: o crescimento profissional posterior de alguns;

Entrevistado 13: recreação, reunião dos alunos.

Dados da pesquisa (20|8).

Destacam-se nas falas dos entrevistados as mais diversificadas lembranças: comemorações, brincadeiras, o modo como a professora ensinava, a estrutura física da escola, em suma, passagens de um tempo em que as coisas corriam num fluxo de aparente calmaria, tranquilidade e paz. Ao terem estas características removidas de seu convívio social, cria-se para estes indivíduos uma barreira difícil de ser transposta, caso as condições basilares necessárias não sejam oferecidas.

Escolas despreparadas, tanto profissionalmente quanto estruturalmente, tendem a reproduzir o sistema social vigente (com extrema disparidade entre ricos e pobres), de tal modo que a desigualdade entre as classes, finda por ser legitimada, fortalecida e colocada como algo que deva ser aceito, sem discussões (SAVIANI, 1981 ; 2008).

Quando questionados acerca de qual era sua melhor recordação da antiga escola da comunidade, no assentamento Riacho Azul, obteve-se os seguintes pontos de vista: 


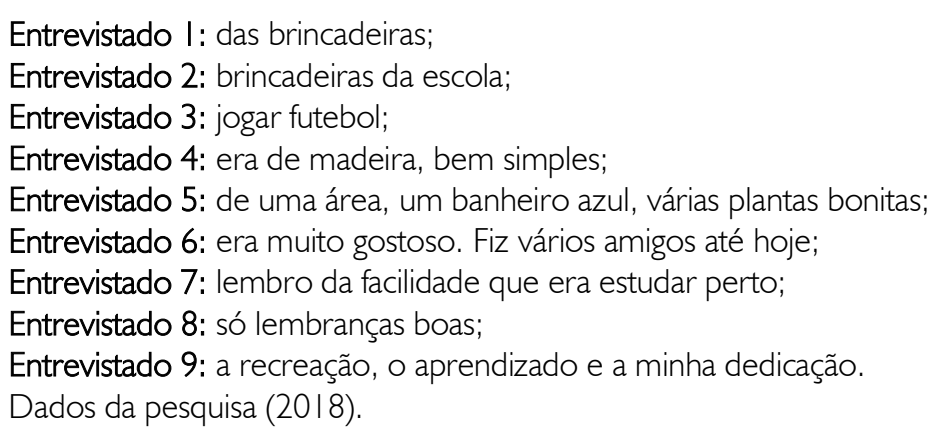

Percebe-se nas argumentações dos entrevistados I, 2, 3 e 9 que as melhores recordações estão vinculadas principalmente ao aspecto lúdico que o lazer proporciona na escola, sendo que este está ligado interdisciplinarmente ao processo de ensino e aprendizagem. Para os entrevistados 4 e 5 as lembranças são alusivas ao aspecto estrutural da escola, denotando um ambiente amigável e acolhedor. Os entrevistados 6, 7 e 8 relatam as amizades que fizeram, a proximidade física da escola na comunidade.

Uma escola que vise à formação cidadã e, sobretudo uma formação humanizadora, deve deixar de lado os paradigmas que a constituíram no decorrer dos anos (discriminatório, excludente e segregador), ou seja, de boa formação para uma minoria privilegiada e má formação para uma maioria excluída e oprimida. É necessário que se afaste da escola o viés ideológico de que esta, atualmente oferece uma educação com as mesmas chances e qualidade para todos, que não existe exploração entre as classes sociais. Basta que se olhe de frente a realidade cruel que as classes menos favorecidas passam no tocante à educação e, facilmente, se perceberão os retrocessos avassaladores causados por este tipo de postura da escola. No entender de Frigotto (2010) a escola ainda que imediatamente improdutiva, é fundamental, pois com o passar do tempo torna-se (mediatamente) produtiva.

Ao serem questionados em relação às melhores recordações da escola na antiga comunidade, os entrevistados do assentamento São Domingos deram os seguintes relatos:

\footnotetext{
Entrevistado I: não tinha escola;

Entrevistado 2: das brincadeiras e dos amigos da escola;

Entrevistado 3: era dentro da comunidade e perto da associação de moradores;

Entrevistado 4: que foi construída pela comunidade;

Entrevistado 5: ser dentro da comunidade;

Entrevistado 6: era dentro da comunidade;

Entrevistado 7: a escola se aproximava do trabalho das crianças;

Entrevistado 8: é porque era dentro de nossa comunidade e servia para todos moradores da comunidade, uns que moravam mais próximo;

Entrevistado 9: a conquista da aprendizagem das pessoas;

Entrevistado 10: bem boa;

Entrevistado I I: festas de São João;

Entrevistado 12: apesar das dificuldades, havia muito esforço para realização das atividades. Dados da pesquisa (20|8)
}

Começa-se destacando o discurso dos entrevistados 3, 5, 6 e 8 reportando que a melhor lembrança estava na proximidade física da escola com a comunidade e como isso era bom para eles. Para os entrevistados 2 e II as melhores recordações são dos amigos e das festas em datas comemorativas 
que faziam na escola. Outro ponto de destaque nos discursos é a escola ter sido construída pela própria comunidade, segundo o entrevistado 4. No entanto, o entrevistado I disse não haver escola na sua comunidade, portanto, não moravam no mesmo local. Na fala do entrevistado 7, um detalhe chama bastante atenção: "trabalho das crianças", ou seja, naquele período as crianças desta comunidade já trabalhavam e, de certo modo, a escola buscava trazer elementos deste labor para dentro do conteúdo escolar. Os entrevistados 9 e 12 apontam como melhor recordação a obtenção do aprendizado ainda que este fosse fruto de muitas dificuldades.

Por meio da análise dos relatos obtidos com os entrevistados de SDO, pode-se observar que a escola funcionava de modo análogo às demais apresentadas anteriormente (exceto pela fala do entrevistado 7), pois sua presença física dentro da comunidade está ainda muito evidenciada como fato essencial. Outras peculiaridades que poderiam ser mencionadas como potencial transformador da escola: a preparação dos estudantes para aprender a lidar com a realidade vivenciada pela comunidade; para o exercício da cidadania e mercado de trabalho; aspectos de qualidade da educação oferecida, não foram apontadas, ou seja, a escola se apresenta fora do contexto social em que viviam, favorecendo e intensificando desse modo a reprodução de valores que nada tem que ver com o dia-a-dia da comunidade.

Passando para a análise nos reassentamentos da margem direita, questionou-se aos entrevistados de Nova Vila de Teotônio a respeito de suas melhores recordações da escola na antiga comunidade, estes informaram as seguintes memórias:

Entrevistado I: direção bem melhor;

Entrevistado 2: era o colégio que era de primeira categoria, os professores, diretora;

Entrevistado 3: a união da comunidade para fazer a escola funcionar;

Entrevistado 4: a quantia de alunos maior, mais moradia e pessoas sobrevivendo na localidade;

Entrevistado 5: as quadrilhas;

Entrevistado 6: o fim de ano quando passava de ano tinha comemoração, dia dos pais, mães;

Entrevistado 7: os professores eram muito bons, a diretora também;

Entrevistado 8: quando nós cantava o hino; (Sic)

Entrevistado 9: da cachoeira que tinha lá, boa e bonita;

Entrevistado 10: a escola era o ponto de referência da comunidade, tinha o maior apreço:

Entrevistado I I: interação com a comunidade, as festas, uma ótima relação;

Entrevistado 12: as brincadeiras, a cultura, a quadrilha;

Entrevistado 13: as festas;

Entrevistado 14: vendia muito na cantina para os alunos.

Dados da pesquisa (20|8).

Percebe-se nas falas dos entrevistados 5, 6, II, 12 e 13 a recordação voltada para as datas comemorativas e festivas que envolviam a escola e comunidade, evidenciando que a comunidade era bastante ligada por meio desses eventos culturais e simbólicos presentes até hoje no imaginário dos moradores. Para os entrevistados I, 2 e 7 o que os fazia lembrar da escola era o fator humano que compunha a escola (os professores, a diretora), revelando a proximidade e afinidade entre escola e comunidade. Os entrevistados 3 e 10 reforçam que havia união da comunidade para o bom funcionamento da escola e esta era a referência e o ponto de encontro dos moradores. 
Embutido no discurso dos entrevistados 4 e 14 está a memória do quantitativo de estudantes e pessoas morando na vila e frequentando a escola, o que se convertia numa economia mais ativa e melhores condições de vida. Lembraram também da beleza do Rio Madeira, retratada na Cachoeira do Teotônio que também fornecia enorme quantidade de pescado e ponto turístico da região. Revelam também o período (provavelmente nos anos 80 do século passado) resquícios de uma educação militar e tradicional em que os estudantes ficavam perfilados e cantavam o Hino Nacional na escola todas as manhãs.

Por meio da análise do conteúdo embutido no discurso dos entrevistados de NVT percebe-se que a escola foi desenvolvida primordialmente (ou exclusivamente?) para preservar e sustentar os privilégios das classes sociais dominantes, visto que a educação escolar destes é mais voltada para funções valorizadas socialmente (como o domínio das artes, das linguagens, das culturas), enquanto que a formação escolar para os oprimidos atua de modo a formar pessoas obedientes (incapazes de reflexões que afetem o status quo) e mão de obra para atender ao mercado de trabalho (subempregos).

Ao serem questionados com relação a suas melhores recordações da escola na antiga comunidade, os entrevistados do reassentamento Parque dos Buritis informaram as seguintes lembranças:

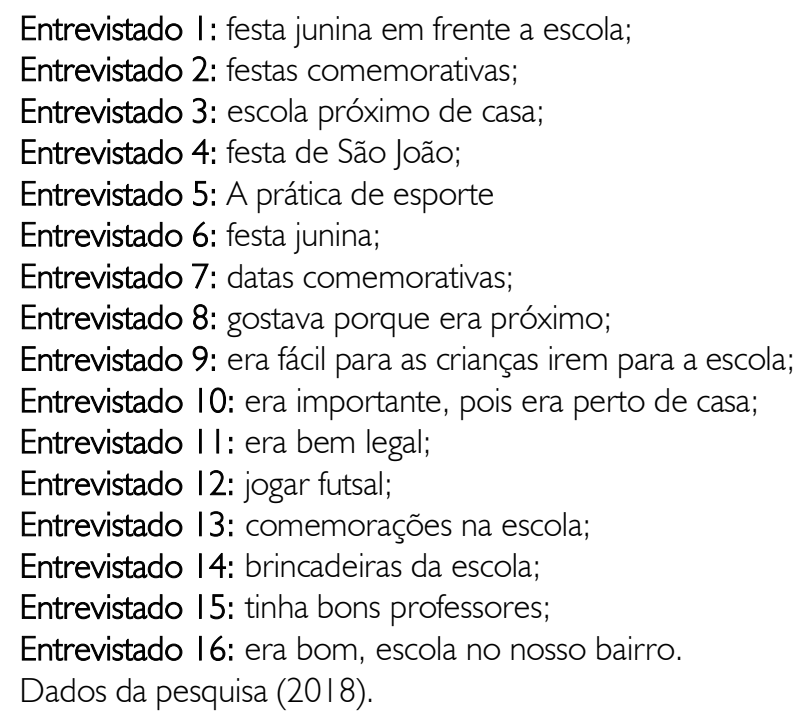

Arraigada aos discursos dos entrevistados I, 2, 4, 6, 7 e 13 existe a presença das memórias referentes aos dias festivos que ocorriam na escola, dos quais o maior destaque para as festividades juninas. Para os entrevistados 3, 8, 9, 10 e 16 o que mais se recordam é da presença da escola no bairro. Os entrevistados 5, 12 e 14 se lembram das atividades recreativas, esportivas e de lazer que havia na escola do bairro. 0 entrevistado II relata que era bem legal, enquanto o entrevistado I 5 se recordou da boa qualidade dos professores.

Nos relatos acima, é possível observar que a escola é vista como importante primeiramente, pela sua presença física, tendo reduzida sua contribuição para a construção de indivíduos críticos e reflexivos, capazes de entender a real importância da dimensão escolar para romper os elos de dominação subjacentes às comunidades de regiões periféricas. Outro aspecto que sobressai aos discursos é o uso dos eventos culturais e 
festivos voltados principalmente para a cultura nordestina, tornando estes quase exclusivos e postos/impostos como valores únicos a serem festejados, desta forma, desvalorizando, impossibilitando e dando uma conotação às manifestações da cultura local de origem indígena e ribeirinha como impróprias ou inferiores. Percebe-se aqui, que a escola não vem pensando o seu projeto político pedagógico a partir de sua realidade local.

Quando questionados acerca de suas melhores recordações da escola na antiga comunidade, os entrevistados do reassentamento Santa Rita informaram as seguintes lembranças:

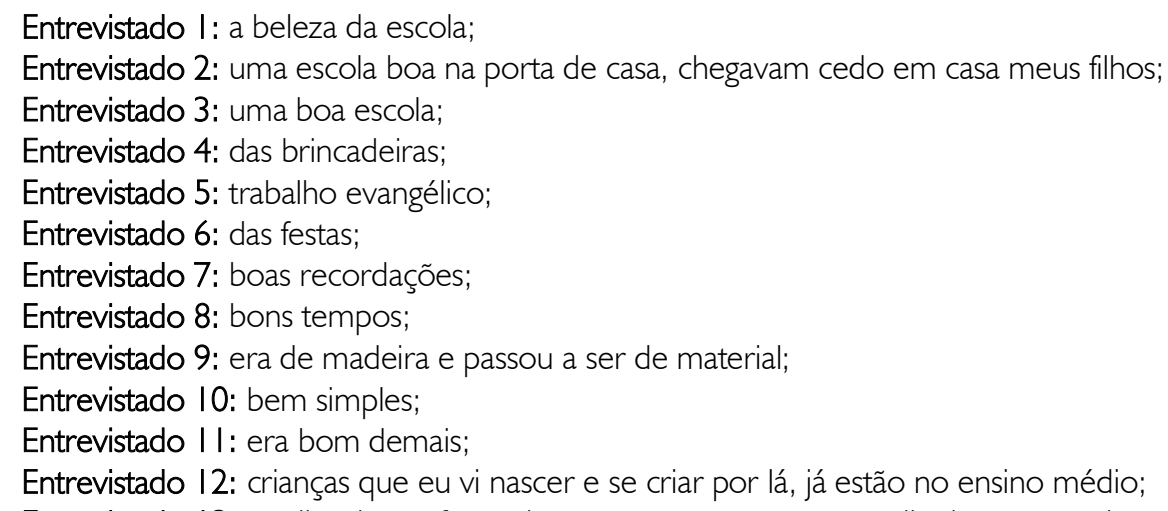

Entrevistado 13: os dias de confraternização, uns com os outros, dia das mães, crianças levavam bolos e refrigerantes;

Entrevistado |4: jogar futebol;

Entrevistado 15: reuniões entre todos os períodos comemorativos;

Entrevistado 16: os períodos comemorativos.

Dados da pesquisa (2018).

Observa-se nas falas dos entrevistados 2, 3, 7, 8 e II que as boas recordações da escola estão relacionadas com a qualidade da escola, revelando um ambiente escolar aprazível. Os entrevistados 6, I3, I 5 e 16 lembram-se da escola pelas comemorações que, segundo eles eram vários períodos do ano. Para os entrevistados 1, 9 e 10 as memórias são da estrutura da escola: que era simples, bela, de madeira e que passou a ser de alvenaria. Os entrevistados 4 e 14 mencionaram a questão da recreação e do esporte na escola. Já o entrevistado 5 disse se lembrar do trabalho de cunho religioso que havia na escola, enquanto o entrevistado 12 se recorda dos avanços na aprendizagem de alguns estudantes que progrediram no ensino formal em função da escola na comunidade.

Todas as escolas (independente de serem de áreas urbanas ou rurais) deveriam acompanhar os avanços ocorridos na sociedade no decorrer dos anos e, mais fortemente, nas últimas quatro décadas. Contudo, o que se percebe é que esta persiste num paradigma que faz acentuar as desigualdades sociais, não acompanha as transformações tecnológica, política e econômica (principalmente) ao se trabalhar conteúdos deslocados da realidade local.

Quando se inquiriu os entrevistados do reassentamento Morrinhos acerca de suas melhores recordações da escola na antiga comunidade, estes informaram as seguintes lembranças:

Entrevistado I: 7 de setembro e das brincadeiras;

Entrevistado 2: do dia 7 de setembro;

Entrevistado 3: não lembro; 


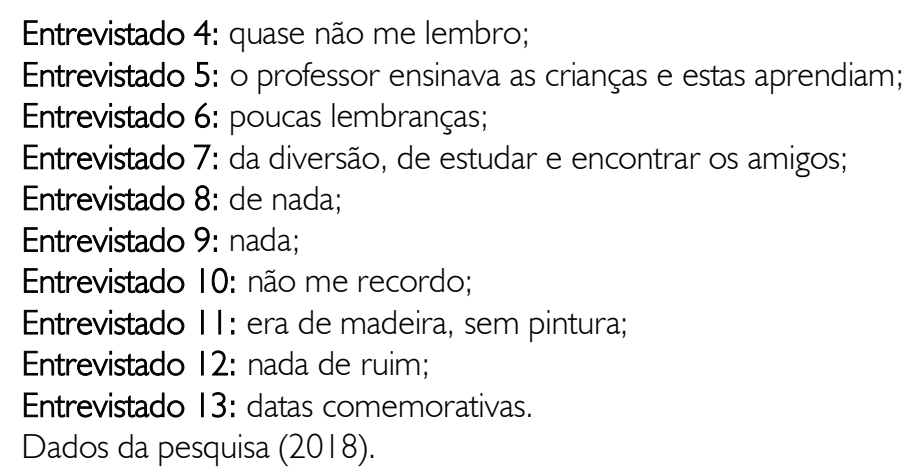

Encontra-se no discurso dos entrevistados 3, 4, 6, 8, 9 e 10 que não houve o que dizer acerca de boas recordações da escola, tendo em vista o próprio argumento destes. Os entrevistados I, 2 e I3 têm boas recordações das datas festivas, em especial o dia da independência do Brasil. Para os entrevistados 5 e 7 as lembranças boas têm relação com o aprendizado, com as amizades, com as brincadeiras. $\bigcirc$ entrevistado I I rememorou a estrutura da escola, sem pintura e feita de madeira, enquanto o entrevistado 12 disse não ter lembranças ruins da escola (nem boas).

Pode-se extrair do discurso dos entrevistados de MOR a ideia de uma educação popular pública oferecida pelo Estado, que no entendimento desta pesquisa, deveria ser rejeitada, haja vista que suas características são incapazes de produzir um cidadão crítico e reflexivo em várias dimensões (social, econômica, física e psicológica). Desta forma, acredita-se que as pessoas estão tão tomadas pelas suas obrigações do cotidiano (exploração do trabalho), quer seja de zonas urbanas ou rurais que o tempo passado na escola, vem tão somente formando "besta de carga", ou seja, o indivíduo se torna, segundo Marx (1974, p. 98), uma "simples máquina, fisicamente destroçada e espiritualmente animalizada, para produzir riqueza alheia".

Entende-se nesta pesquisa que a instituição educacional pública deve partir rumo a uma nova perspectiva didática e pedagógica. Tamanho desafio posto aos educadores do século $X X I$ não será tarefa fácil de cumprir. Entretanto, tais mudanças emergem por pressão social, para que a escola deixe de ser atrelada e reconhecida como aquela favorecedora das classes dominantes e opressoras, passando a extrapolar sua função eminentemente pedagógica e cumprindo seu enorme cabedal de funções sociais (ALVES, 2006).

\section{CONCLUSÃO}

Evidenciou-se, por meio dos dados, que os entrevistados reconhecem a importância da escola, ainda que esta não ofereça as melhores possibilidades de aprendizado. Caberia, portanto, partindo do conhecimento prévio desta realidade, que as compensações sociais para o remanejamento de pessoas, olhassem com o devido cuidado para a escola favorecendo-a e fortalecendo-a. 
Percebeu-se, no discurso dos entrevistados, certa inocência (entendida aqui como falta de discernimento ou desconhecimento de seus direitos) própria de pessoas simples, humildes e com pouca instrução formal. Diga-se de passagem, que a razão deste pensamento ocorreu ao verificar que boa parte dos entrevistados pensa a educação escolar como apenas ler e escrever, pois foi isto que a escola proporcionou para eles. Eis a razão do indicativo de saber o "bê-á-bá" como motivo preponderante da escola ser boa, ou somente pela oportunidade de aprender alguma coisa na escola da comunidade, mesmo sendo esta simplória. É justamente esta simplicidade e fragilidade, que torna estas populações vulneráveis aos mais graves desmandos do capitalismo.

Destaca-se também, nas falas dos entrevistados, a empatia entre professores e comunidade, relação de respeito e carinho; os casos de sucesso escolar em que os estudantes avançaram nos estudos chegando à faculdade. Do mesmo modo, relataram também a necessidade de melhoria da educação rural, a alta procura por vagas, a organização da escola, mesmo com as dificuldades vigentes. Todas as adversidades apontadas pelos moradores não fizeram com que diminuísse a sensação de boas recordações de suas antigas comunidades.

Evidenciou-se que o cotidiano da escola é cercado de precariedade, por vezes são turmas multisseriadas, escolas apenas para o primeiro seguimento do ensino fundamental, a estrutura é precária, tem poucos professores, os profissionais têm que desempenhar várias atividades além da sala de aula, persiste a falta de transporte prejudicando o ano letivo. $O$ número de moradores nos assentamentos vem diminuindo, colocando em xeque a permanência e a justificativa da escola na comunidade, não existe espaço adequado para o desenvolvimento de atividades lúdicas e de educação física, em alguns casos faltam merenda escolar para os estudantes, não há manutenção da escola e, sobretudo, em alguns locais apresentam sub aproveitamento do espaço.

Diante de tantas mudanças (territoriais, materiais, simbólicas, sociais) que os reassentados terão que enfrentar e vem enfrentando, principalmente os novos papeis sociais que terão de desempenhar (em que pescadores deixam de pescar por conta da insuficiência de peixes no rio que antes era abundante, agricultores que deixam de plantar em razão da terra não ser mais tão boa para o plantio). Entende-se que, caso não haja esforços efetivos e política públicas para o enfrentamento desta nova realidade, essas comunidades tendem a sucumbir à pobreza (de recursos naturais e materiais) e à nostalgia (retratada em suas faces, hoje de aparência tão triste) por estarem morando num território não compatível com suas habilidades.

Conclui-se que, se mesmo diante de toda essa memória individual e coletiva no tocante à escola, esta for suprimida nos seus preceitos fundamentais (aqui entendidos como: aprender a conhecer, aprender a fazer, aprender a conviver e aprender a ser) como possibilitar a reconfiguração do espaço social e reterritorialização das comunidades deslocadas, expulsas de seus territórios, sem o devido cuidado com a educação escolar? 


\section{REFERÊNCIAS}

ALVES, G. L. A produção da escola pública contemporânea. $4^{\mathrm{a}}$ ed. Campinas: Autores Associados, 2006.

ARAÚJO, N. C.; MORET, A. S. Direitos humanos e hidrelétricas: uma análise dos impactos socioambientais e econômicos gerados em Rondônia. Revista Veredas do Direito, v. I3, n. 26, p. 167194, maio/ago. 2016. Disponível em: http://www.domhelder.edu.br/revista/ index.php/veredas/article/view/622. Acesso em: 03 fev. 2017.

BARDIN, L. Análise de conteúdo. Lisboa: Edições 70, 1979.

BERMANN, C. Energia no Brasil: Para quê? Para quem? Crise e Alternativas para um país sustentável. São Paulo. Livraria Física, 2002.

BERMANN, C. Impasses e Controvérsias da Hidreletricidade. 2007. Disponível em: www.fem.unicamp.br/ seva/ArtCelioBERMANNEstudAvan_ABRIL07.pdf. Acesso em: 08 fev. 2017.

BRASIL. Lei n 9.394, de 20 de dezembro de 1996. Estabelece as diretrizes e bases da educação nacional. Disponível em: http://www.planalto.gov.br/ccivil 03/leis/19394.htm. Acesso em: I 5 mai. 2016.

CARRACEDO, J. R. Ciudadania Compleja y Democracia. In. CARRACEDO, J. R; ROSALES, J. M; MÉNDEZ, M. T. (orgs). Ciudadania, Nacionalismo y Derechos Humanos. Madri: Editorial Trotta, 2000, p. $21-45$.

ESCOBAR, A. Sentipensar con la tierra. Nuevas lecturas sobre desarrollo, territorio y diferencia. Medellín: Ediciones UNAULA, 2014.

FEARNSIDE, P. M. Estado, Energia Elétrica e Meio Ambiente: $O$ caso das Grandes Barragens. Coordenação dos Programas de Pós-Graduação em Engenharia da Universidade Federal de Rio de Janeiro (COPPE/UFRJ), Rio de Janeiro: 1995.

FEARNSIDE, P. M. Hidrelétricas na Amazônia: Impactos Ambientais e Sociais na Tomada de Decisões sobre Grandes Obras, v. I. Manaus: Editora do Instituto Nacional de Pesquisas da Amazônia (INPA), 2015.

FEARNSIDE, P. M. Hidrelétricas na Amazônia: impactos ambientais e sociais na tomada de decisões sobre grandes obras. Manaus: Editora do INPA, 2019.

FREIRE, P. Política e educação: ensaios. 5. ed., São Paulo: Cortez, 200I .

FRIGOTTO, G. A produtividade da escola improdutiva. Um (re)exame das relações entre educação e estrutura econômico-social capitalista. D 9a edição. São Paulo: Cortez, 2010.

GIONGO, C. R.; MENDES, J. M. R.; SANTOS, F. K. Desenvolvimento, saúde e meio ambiente: contradições na construção de hidrelétricas. Serviço Social e Sociedade, São Paulo, n. 123, p. 50 I -522, set. 20 I 5. Disponível em: http://dx.doi.org/l 0. 1590/0 I0 I-6628.034. Acesso em: I 4 fev. 2017.

LIBÂNEO, J. C. Democratização da Escola Pública: A Pedagogia Crítico-Social dos Conteúdos. 19a ed, São Paulo: Edições Loyola, 2002. Disponível em: https://docs.google.com/file/d/OB8jeXMvFHiDc3FtRFRnd IIMN00/edit. Acesso em: I 4 de mai. 2018.

MANACORDA, M. A. Marx e a pedagogia moderna. $2^{\text {a }}$ ed. Campinas, SP: Editora Alínea, 2010. 
MARX, K. Salário, preço e lucro. In: CIVITA, V. (Ed.) Os pensadores: Karl Marx. São Paulo: Abril Cultural, 1974, p.63-105.

MINAYO, M. C. S. (org.). Pesquisa Social. Teoria, método e criatividade. I 8 ed. Petrópolis: Vozes, 2001 .

MORET, A. S.; SILVA, L. L. C. E. O Rio Madeira, uma sociedade e a Indústria da Energia: a construção das Usinas Hidrelétricas e os impactos e intervenções na sociedade. Boletim do Observatório Ambiental Alberto Ribeiro Lamego, v. 4, p. II-31, 2010.

MORET, A. S.; GUERRA, S. M. G. Hidrelétricas no Rio Madeira: Reflexões sobre Impactos Ambientais e Sociais. Oídles (Málaga), v. 3, p. I - 10, 2009. Disponível em:

http://www.eumed.net/rev/oidles/07/smgg.htm. Acesso em: 07 fev. 2017.

PONCE, A. Educação e luta de classes. 19a ed. São Paulo: Cortez, 2001.

SANTOS, M. O dinheiro e o território. GEOgraphia, v. I, n. I , p. 7- 13, 1999. Disponível em: http://www.geographia.uff.br/index.php/geographia/article/viewFile/2/2. Acesso em: I4 jun. 20 I 8.

SANTOS, A. R. Educação do campo e agronegócio: território de disputas. Educação em Revista, Marília, v. I8, n.2, p. 7I-90, jul.-dez., 2017.

SAVIANI, D. Escola e Democracia. $4^{a}$ ed. Coleção Polêmicas do nosso tempo. São Paulo: Autores Associados e Editora Cortez, 1981.

SAVIANI, D. Escola e Democracia. Coleção Educação Contemporânea. Ed. Comemorativa. Campinas, São Paulo: Autores Associados, 2008.

SECRETARIA MUNICIPAL DE EDUCAÇÃO (Porto Velho). Plano Municipal de Educação. 2015. Disponível em:

http://www.avaliacaoinstitucional.unir.br/uploads/87878787/5604_2015 pme_prefeitura_porto velho_r o_ (plano municipal de educacao de porto velho).pdf . Acesso em: I I jul. 2018.

VAINER, C. B. Recursos hidráulicos: questões sociais e ambientais. Estudos Avançados. 2007.

VAINER, C. Conceito de "atingido": Uma revisão do debate. In: ROTHMAN, F. D. (Org.). Vidas

Alagadas - Conflitos Socioambientais. Viçosa: FGV, 2008. 


\section{COMO CITAR ESSE ARTIGO}

\section{Associação Brasileira de Normas Técnicas (ABNT)}

SILVA, Jeferson Cardoso da; MORET, Artur de Souza. A Educação Escolar em assentamentos de hidrelétricas: memórias de um povo esquecido. Debates em Educação, Maceió, v. 12, p. 37-59, dez. 2020. ISSN 2175-6600. Disponível em:

https://www.seer.ufal.br/index.php/debateseducacao/article/view/8764. Acesso em: dd mmm. aaaa.

\section{American Psychological Association (APA)}

Silva, J., \& Moret, A. (2020). A Educação Escolar em assentamentos de hidrelétricas: memórias de um povo esquecido. Debates em Educação, 12(Esp2), 37-59. doi: https://doi.org/l0.28998/21756600.2020v12nEsp2p37-59 